\title{
Reiterated repeat region variability in the ciliary adhesin gene of Mycoplasma hyopneumoniae
}

\author{
Jody L. Wilton, ${ }^{1,3}$ Anthony L. Scarman, ${ }^{2,3}$ Mark J. Walker ${ }^{1}$ \\ and Steven P. Djordjevic ${ }^{3}$
}

Author for correspondence: Steven P. Djordjevic. Tel: +61246406426 . Fax: +61246406384. e-mail: steve.djordjevic@agric.nsw.gov.au

1 Department of Biological Sciences, University of Wollongong, Wollongong, NSW, Australia

2 School of Biotechnology, University of New South Wales, Sydney, NSW, Australia

3 Microbiology and Immunology Section, Elizabeth Macarthur Agricultural Institute, PMB 8, Camden, NSW Australia 2570
Mycoplasma hyopneumoniae is a highly prevalent pathogen which colonizes the ciliated epithelial lining of the porcine respiratory tract. Expression libraries constructed from genomic DNA of the non-pathogenic strain $M$. hyopneumoniae J were screened with porcine hyperimmune antiserum against $M$. hyopneumoniae. One clone expressed a 28 kDa protein which was also reactive with monospecific antiserum raised against a putative $M$. hyopneumoniae-specific $94 \mathrm{kDa}$ antigen derived from strain J. Trypsin digestion of whole $M$. hyopneumoniae cells showed the 94 kDa antigen to be surface-accessible. DNA sequence analysis of the gene encoding the $94 \mathrm{kDa}$ antigen revealed greater than $\mathbf{9 0} \%$ homology to two adhesin genes, encoding P97 and Mhp1, cloned from pathogenic strain 232 and strain P5722 of M. hyopneumoniae, respectively. Two regions of repetitive DNA sequence were identified in the gene encoding the $94 \mathrm{kDa}$ antigen. The first encoded the deduced amino acid sequence $A(T)-K-P-E(V)-A(T)$ arranged as nine tandem repeats (RR1). The second region of repetitive DNA sequence encoded the deduced amino acid sequence G-A(E,S)-P-N(S)-Q-G-K-K-A-E arranged as five tandem repeats (RR2). Comparison of the three $M$. hyopneumoniae adhesin genes revealed that the genes encoding P97 and Mhp1, and the strain J gene encoding the $94 \mathrm{kDa}$ antigen contained 15, 12 and 9 tandem repeats, respectively, in RR1, and 4, 5 and 5 tandem repeats, respectively, in RR2. Southern hybridization analysis of EcoRl-digested genomic DNA probed with an 820 bp fragment spanning RR1 and RR2 identified a strongly hybridizing fragment ranging in size from 2.15 to $2.30 \mathrm{~kb}$ among seven geographically diverse strains of $\boldsymbol{M}$. hyopneumoniae but failed to hybridize with DNA from four strains of Mycoplasma hyorhinis or Mycoplasma flocculare strain Ms42. PCR primers flanking the DNA sequence encoding RR1 and RR2 were used to amplify DNA from the seven strains of $M$. hyopneumoniae and DNA sequence analysis of the amplification products showed that the number of tandem amino acid repeats in RR1 varied considerably between strains. RR1 from $M$. hyopneumoniae strains YZ, Beaufort, Sue, OMZ407 and C1735/2 comprised $11,15,12,15$ and 8 tandem copies, respectively, of the 5-aa repeat whilst RR2 comprised 4, 3, 4, 3 and 4 tandem copies, respectively, of the 10-aa repeat. Two putative integrin binding sites (L-E-T and R-X-X-X-D) were identified in the $94 \mathrm{kDa}$ ciliary adhesin. Variability in the number of amino acid repeats in RR1 amongst strains of $M$. hyopneumoniae may influence ciliary binding.

Keywords: Mycoplasma byopneumoniae, pathogenesis, adhesin, antigenic size variation 


\section{INTRODUCTION}

Mycoplasma hyopneumoniae attaches to the ciliated epithelial cells lining the porcine respiratory tract, inducing loss of cilial function and a chronic inflammatory response which results in pneumonia and causes significant losses to swine production (Tajima \& Yagihashi, 1982; Clark et al., 1991). Mycoplasma membranes are rich in protein, many of which stimulate a humoral immune response in the host (Razin, 1979). Although several immunoreactive $M$. hyopneumoniae antigens have been characterized and their genes cloned (Klinkert et al., 1985; Haldimann et al., 1993, Fagan et al., 1996), attempts to identify surface components which play a role in early colonization have only recently been reported. The development of microtitre plate adherence and TLC overlay assays has revealed that $M$. byopneumoniae binds to sulfated glycolipid receptors present on porcine respiratory tract ciliated cells and that heparin, fucoidan, mucin and chondroitin interact with adhesive molecules on the surface of $M$. byopneumoniae and are able to disrupt the adherence of the pathogen to intact ciliated cells (Zhang et al., 1994a, b). In addition, two mAbs (F2G5 and F1B6) which predominantly recognize a $97 \mathrm{kDa} M$. hyopneumoniae antigen inhibited adherence by up to $67 \%$ in a microtitre plate adherence assay (MPAA) (Zhang et al., 1995). $\mathrm{mAb}$ F2G5 recognized several antigens ranging in molecular mass from 65 to $125 \mathrm{kDa}$ in immunoblotting studies of whole-cell lysates of different strains of $M$. byopneumoniae and the immunoblot profiles varied among these strains (Zhang et al., 1995). In addition, low-passage strains of $M$. byopneumoniae adhered strongly to porcine cilia in an MPAA whilst the highpassage strain $\mathrm{J}$ displayed significantly reduced adherence (Zhang et al., 1995).

Hsu et al. (1997) cloned, sequenced and expressed a gene encoding P97 from M. hyopneumoniae strain 232 . The P97 coding region contained two regions of repetitive DNA sequence in the carboxy terminus. One of the repetitive regions encoded amino acids $A(T)-K-P-E(V)-$ $A(T)$ repeated 15 times (RR1) and the second region encoded amino acids G-A(E,S)-P-N(S)-Q-G-K-K-A repeated four times (RR2). The role of P97 in adherence to cilia was confirmed using transposon-induced mutations within the P97 coding sequence to eliminate reactivity to mAb F1B6. Tn1000 insertional mutagenesis studies mapped the mAb F1B6 binding epitope to a region between amino acid residues 704 and 1004 in the carboxy terminus of P97 which encompassed the 5-aa repeat region (RR1) but not the 10 -aa repeat region (RR2). The insertion of Tn 1000 in RR2 did not affect ciliary binding or the ability of mAb F1B6 to bind to P97, suggesting that RR2 is not involved in adhesion (Hsu et al., 1997). DNA sequence analysis revealed the presence of an ORF for a $124 \mathrm{kDa}$ protein; however amino-terminal sequence analysis of P97 (Zhang et al., 1995) mapped 195 aa internal to the start codon, suggesting that the $124 \mathrm{kDa}$ antigen was a precursor in M. byopneumoniae that is subsequently processed to $102 \mathrm{kDa}$ by proteolytic cleavage (Hsu et al., 1997).
Preliminary DNA sequence analysis of the gene encoding a $28 \mathrm{kDa}$ immunoreactive antigen from the avirulent strain $M$. byopneumoniae J showed homology to the carboxy-terminal portion of a ciliary adhesin characterized from pathogenic strain 232 (accession no. U50901). The aim of this project was to clone, sequence and characterize the gene encoding the ciliary adhesin from the avirulent strain M. byopneumoniae $\mathrm{J}$ and to investigate variations in gene sequence, particularly in the reiterated repeat regions, among geographically diverse strains of this pathogen. In addition, we investigated the surface accessibility of the adhesin and determined if pigs infected with $M$. byopneumoniae elicited a serum antibody response which recognized this antigen.

\section{METHODS}

Bacterial strains, plasmids and culture conditions. Plasmid vectors pET23a, b and $c$ (Novagen) in conjunction with Escherichia coli BL21(DE3)(pLysS) cells were used to produce the $M$. byopneumoniae strain J library. E. coli strains XL-1 Blue (Stratagene) and BL21(DE3) (pLysS) (Novagen) were used to amplify and express pAS1, respectively. E. coli strains were grown in Luria-Bertani (LB) medium or on LB agar (Sambrook et al., 1989) supplemented with ampicillin (100 $\mu \mathrm{g}$ $\left.\mathrm{ml}^{-1}\right)$ and chloramphenicol $\left(32 \mu \mathrm{g} \mathrm{ml}^{-1}\right)$ where required.

Mycoplasma strains and culture conditions. $M$. byopneumoniae strains J (NCTC 10110), Beaufort, Sue, C1735/2 and OMZ407, M. hyorbinis strains BTS-7, GDL, field strains 1 and 2 and $M$. flocculare type strain Ms42 were obtained from the Australian Mycoplasma Reference Collection (AMRC, University of South Australia). Australian isolates Beaufort, Sue, C1735/2 and OMZ407 were originally recovered from porcine lungs with lesions typical of enzootic pneumonia and are low-passage isolates (Scarman et al., 1997). M. hyopneumoniae strains YZ (France) and 232 (USA) were obtained from M. Kobisch (Ploufragan, France) and T. Young (Iowa State University, USA), respectively. All strains were cultured as described previously (Scarman et al., 1997). Briefly, each was grown in modified Friis medium at $37^{\circ} \mathrm{C}$ and harvested in the $\mathrm{pH}$ range $6 \cdot 9-7 \cdot 2$ as indicated by a colour change. Mycoplasmas were harvested by centrifugation at $7000 \mathrm{~g}$ for $20 \mathrm{~min}$ and the pellet washed three times with TBS (10 mM Tris/ $\mathrm{HCl}, 0.9 \% \mathrm{NaCl}, \mathrm{pH} 7.4)$. The identity of all strains of $M$. hyopneumoniae and $M$. flocculare strain Ms42 was confirmed using species-specific PCR primers which amplified portions of the $16 \mathrm{~S}$ rRNA gene of these two species (Stemke et al., 1994).

Preparation of antisera. Preparation of porcine hyperimmune antiserum against $M$. byopneumoniae has been described previously (Scarman et al., 1997). Two pigs from a herd known to be free of $M$. hyopneumoniae were bled (prebleed) and the serum used to confirm the absence of antibodies against $M$. hyopneumoniae by immunoblotting and ELISA. A freshly grown culture of $M$. byopneumoniae was harvested, washed and the final pellet $(1.0 \mathrm{~g})$ was resuspended in TBS. An aliquot $(1 \mathrm{ml})$ containing approximately $250 \mathrm{mg}$ of $M$. byopneumoniae was emulsified with an equal volume of Freund's complete adjuvant and used to inoculate each pig intramuscularly (i.m.) in the neck and rump ( $1 \mathrm{ml}$ in each site). One month later, $2 \mathrm{ml}$ of a booster inoculum was prepared 
using Freund's incomplete adjuvant and administered as before. Serum responses were monitored weekly thereafter until an anti-M. hyopneumoniae response was observed by immunoblotting and ELISA (Scarman et al., 1997).

Rabbit hyperimmune serum was raised against recombinant $28 \mathrm{kDa}$ (carboxy-terminal portion of the adhesin), $94 \mathrm{kDa}$ (full adhesin) and $36 \mathrm{kDa}$ (lactate dehydrogenase) $M$. byopneumoniae antigens. The $28 \mathrm{kDa}$ antigen was prepared as described by Djordjevic et al. (1994) with the following modifications. Polyacrylamide gels $(12 \%)$ prepared with a single sample well were loaded with 491 Prep Cell-purified (Bio-Rad) $28 \mathrm{kDa}$ antigen (approx. $50 \mathrm{mg}$ ). Gels were stained with Coomassie blue and the band containing the antigen excised, frozen in liquid nitrogen and ground with a mortar and pestle to a fine powder. Antigen was emulsified with Freund's complete adjuvant and then administered i.m. to two New Zealand White rabbits (delivering $0.75 \mathrm{ml}$ to each of the hind legs and $0.25 \mathrm{ml}$ to each front leg). Booster inoculations, delivered 1 month later, consisted of the same dose of the pulverized polyacrylamide/antigen emulsified with Freund's incomplete adjuvant. Rabbit hyperimmune sera against 94 and $36 \mathrm{kDa} M$. byopneumoniae-specific antigens were produced as described above except that each antigen did not require extraction from a gel. Column-purified (491 Prep Cell) 94 and $36 \mathrm{kDa}$ antigens appeared as single bands when resolved by SDS-PAGE and stained with Coomassie blue or immunoblotted using anti-94 and anti-36 kDa antisera, respectively (data not shown).

Experimental infection of pigs with $\boldsymbol{M}$. hyopneumoniae. Six pigs were experimentally infected with $M$. byopneumoniae as described previously (Djordjevic et al., 1997). Briefly, pigs were challenged by intratracheal inoculation with a lung homogenate obtained from pigs previously infected with the virulent Beaufort strain of $M$. byopneumoniae (Etheridge et al., 1979). The presence of $M$. hyopneumoniae in lung tissue routinely used for the preparation of lung homogenate was confirmed using a PCR assay incorporating primers specific for the 16S rRNA gene of this species (Stemke et al., 1994). Pigs were inoculated through an endotracheal tube with $20 \mathrm{ml}$ icechilled lung homogenate (equivalent to $9 \cdot 2 \mathrm{~g}$ wet wt in $20 \mathrm{ml}$ PBS per pig) prepared by cutting infected lung into small pieces, macerating further using a stomacher and filtering through cheese cloth. Prior to inoculation with $M$. byopneumoniae, pigs were sedated with azaperone $\left(2 \mathrm{mg} \mathrm{kg}^{-1}\right.$ i.m.) and anaesthesia was induced, initially with halothane and nitrous oxide via face mask and then more deeply (sufficient for intubation) with thiopentone $\left(3.5 \mathrm{mg} \mathrm{kg}^{-1}\right.$ ) injected via a marginal ear vein.

Cloning of the $3^{\prime}$ end of the $M$. hyopneumoniae strain J adhesin gene. M. byopneumoniae strain J genomic DNA was extracted as described previously (Fagan et al., 1996) and digested with EcoRI. DNA was size-fractionated through $10-40 \%$ sucrose gradients and fragments from 0.5 to $10 \mathrm{~kb}$ were ligated separately into EcoRI-digested pET23a, b and c vectors (Novagen) treated with calf alkaline phosphatase to prevent self-ligation. Ligation products were transformed into competent E. coli BL21(DE3)(pLysS) cells (Novagen). The cells were then inoculated into fresh LB medium and incubated for $2 \mathrm{~h}$ at $37^{\circ} \mathrm{C}$ prior to plating onto LB agar containing chloramphenicol for overnight incubation at $37^{\circ} \mathrm{C}$. Colonies were then blotted onto nitrocellulose, placed on Whatman $3 \mathrm{MM}$ filter paper saturated with $\mathrm{LB}$ medium and $10 \mathrm{mM}$ IPTG and incubated at $37^{\circ} \mathrm{C}$ for $4 \mathrm{~h}$. The blots were then treated with $5.0 \%(\mathrm{w} / \mathrm{v})$ SDS to lyse the cells, gently washed with PBS, blocked by incubation in $5.0 \%(\mathrm{w} / \mathrm{v})$ non-fat milk in TBS and immunostained using porcine hyperimmune $M$. byopneumoniae antiserum which had been extensively adsorbed against E. coli proteins as described by Ro et al. (1994). Potential positive clones were recovered from master plates and the immunoreactivity of recombinant antigens was confirmed by Western blotting.

Protein expression and purification. Recombinant E. coli BL21(DE3) ( $p L y s S$ ) cells containing pAS1 were grown to midexponential phase in LB medium containing the appropriate antibiotics prior to the addition of $10 \mathrm{mM}$ IPTG. After further growth for $4 \mathrm{~h}$, cells were harvested, lysed by heating to $95^{\circ} \mathrm{C}$ in Laemmli reducing mixture (Laemmli, 1970) and sonicated using a Branson Sonifier $(10 \times 30 \mathrm{~s}, 70 \%$ duty cycle over a 5 min period at $4{ }^{\circ} \mathrm{C}$ ) to shear genomic DNA. Whole-cell lysate ( $2 \mathrm{ml}$ loading vol., $0.5 \mathrm{~g}$ wet $\mathrm{wt}$ ) was loaded onto a preparative 491 Prep Cell column $(37 \mathrm{~mm}$ i.d.) containing a $12 \%$ polyacrylamide matrix with $4 \%$ polyacrylamide stacking gel and proteins separated by electrophoresis for $24 \mathrm{~h}$ at $40 \mathrm{~mA}$ constant current. Aliquots $(15 \mu \mathrm{l})$ of fractions $(5 \mathrm{ml})$ were analysed by immunoblotting using porcine hyperimmune antiserum against $M$. byopneumoniae and fractions containing the immunoreactive $28 \mathrm{kDa}$ antigen were pooled and concentrated by ultrafiltration (Amicon).

SDSPAGE and Western blotting. SDS-PAGE and immunoblotting were performed essentially as described by Laemmli (1970) and Burnette (1981), respectively. After blocking in TBS containing $5.0 \%$ non-fat milk for $1 \mathrm{~h}$ and washing $(3 \times 10 \mathrm{~min})$ in TBS containing $0.1 \%$ non-fat milk and $0.05 \%$ Tween 20 , blots were incubated for $1.5 \mathrm{~h}$ with either porcine hyperimmune antiserum against $M$. hyopneumoniae $(1: 500)$ or rabbit anti-28, anti-94 or anti-36 kDa sera $(1: 400)$ in TBS containing $0.5 \%$ non-fat milk. Blots were washed as above before being incubated with either goat anti-pig antibodies (Southern Biotechnologies) or sheep anti-rabbit antibodies (Silenus Laboratories) conjugated with horseradish peroxidase $(1: 2000)$. Blots were again washed $(3 \times 10 \mathrm{~min})$ prior to development with freshly prepared DAB substrate $(0.05 \%$ $3,3^{\prime}$-diaminobenzidene, $0.03 \%$ hydrogen peroxide in $100 \mathrm{mM}$ Tris/ $\mathrm{HCl}, \mathrm{pH} 7 \cdot 4$ ).

ELISA for anti-28 kDa protein antibodies. Preparative SDSPAGE-purified $28 \mathrm{kDa}$ antigen $(100 \mu \mathrm{l}, 80 \mathrm{ng})$ was coated onto 96-well microtitre plates (Flow Laboratories) in carbonate coating buffer $\left(0.15 \% \mathrm{Na}_{2} \mathrm{CO}_{3}, 0.29 \% \mathrm{NaHCO}_{3}, \mathrm{pH} 9.5\right)$ and plates were incubated overnight at room temperature in a humidified chamber. Plates were washed five times with PBS containing $0.05 \%$ Tween 20 using a SLT 96PW plate washer (Titretek). Primary antibody (sera from pigs experimentally infected with $M$. byopneumoniae as described above) was diluted 1:200 in PBS containing 2.0\% non-fat milk and 0.05\% Tween 20,100 $\mu \mathrm{l}$ was added to each well and the plates were incubated in a humidified chamber for $1.5 \mathrm{~h}$ at room temperature. Plates were washed as before, prior to the addition of $100 \mu \mathrm{l}$ goat anti-pig horseradish peroxidase conjugate diluted 1:500 in PBS containing 2.0\% non-fat milk and 0.05\% Tween 20. Plates were then incubated in a humidified chamber for $1 \mathrm{~h}$ at room temperature and washed prior to the addition of $100 \mu \mathrm{l} 1 \mathrm{mM}$ ABTS substrate [2,2'-azino-bis(3-ethylbenzthiazoline-6-sulfate) diluted in citrate phosphate buffer, $\mathrm{pH} 4 \cdot 2]$ to induce colour development. Plates were shaken and read at $405 \mathrm{~nm}$ on an automated plate reader (Labsystems Multiscan Bichromatic).

Trypsin treatment of $M$. hyopneumoniae cells. $M$. byopneumoniae cells $(1 \mathrm{~g})$ were resuspended in $5 \mathrm{ml}$ sterile PBS and aliquots $(500 \mu \mathrm{l})$ were introduced into sterile microcentrifuge tubes. Cell suspensions of $M$. hyopneumoniae and freshly prepared stock solutions of trypsin were pre-incubated to $37^{\circ} \mathrm{C}$. Trypsin was added to cell suspensions of $M$. 
byopneumoniae at $0,0 \cdot 1,0 \cdot 3,0 \cdot 5,1,2,3$ and $5 \mu \mathrm{g} \mathrm{ml}^{-1}$. Cell suspensions were incubated at $37^{\circ} \mathrm{C}$ for $15 \mathrm{~min}$. Immediately after incubation, the suspensions were lysed in Laemmli buffer and heated to $95-98^{\circ} \mathrm{C}(10 \mathrm{~min})$. Cell lysates were analysed by SDS-PAGE and immunoblotting using rabbit anti-28 and anti$36 \mathrm{kDa}$ sera.

DNA sequence analysis of the $3^{\prime}$ end of the $M$. hyopneumoniae adhesin gene. DNA sequencing was performed using purified plasmid (pAS1) DNA (Qiagen) with synthetic oligonucleotide primers supplied commercially (Life Technologies) and the Taq DyeDeoxy Terminator Cycle Kit (Applied Biosystems). PCR was performed using a Perkin Elmer GeneAmp 9600 and DNA sequence reactions were analysed with an Applied Biosystems model 377 automated DNA sequencer. Comparison of the nucleotide and derived protein sequences with databases was performed using the package from the University of Wisconsin Genetics Computer Group (GCG) version 7, accessed via the Australian National Genomic Information Service (ANGIS, University of Sydney).

N-terminal amino acid microsequencing. The first 15 aa residues of the $28 \mathrm{kDa}$ antigen purified by preparative SDSPAGE were sequenced commercially using Edman chemistry with an Applied Biosystems Procise-HT Sequencer located at the Biomolecular Resource Facility, John Curtin School of Medical Research, Australian National University.

Cloning and sequence analysis of the $5^{\prime}$ end of the $M$. hyopneumoniae strain J adhesin gene. Two homologous $M$. byopneumoniae adhesin gene sequences (accession nos U27294 and U50901) were used to design primer 5'F (AGT TAA ATA AAT TTT TCA CT). Primer 5'R (CTT TAA TCT GAT TGT AAG GA) was designed using DNA sequence derived from pAS1. Primers $5^{\prime} \mathrm{F}$ and $5^{\prime} \mathrm{R}$ were used to amplify the $5^{\prime}$ end of the $M$. hyopneumoniae strain J adhesin. A $50 \mu \mathrm{l}$ reaction mixture comprised $200 \mu \mathrm{M}$ deoxyribonucleotide triphosphates, oligonucleotide primers $5^{\prime} \mathrm{F}$ and $3^{\prime} \mathrm{R}(200 \mathrm{nM}$ each), 2 units of AmpliTaq Gold DNA polymerase (Perkin Elmer), $16 \mathrm{mM}\left(\mathrm{NH}_{4}\right)_{2} \mathrm{SO}_{4}, 67 \mathrm{mM}$ Tris/ $\mathrm{HCl}(\mathrm{pH} \mathrm{8.8)}$ and $4 \mathrm{mM} \mathrm{MgCl}{ }_{2}$. The reaction mixture was incubated at $94^{\circ} \mathrm{C}$ for $120 \mathrm{~s}$ for 1 cycle, followed by 35 cycles of denaturation at $94^{\circ} \mathrm{C}$ for $20 \mathrm{~s}$, primer annealing at $59^{\circ} \mathrm{C}$ for $20 \mathrm{~s}$ and extension at $70^{\circ} \mathrm{C}$ for $90 \mathrm{~s}$. A final cycle consisting of $94^{\circ} \mathrm{C}$ for $20 \mathrm{~s}$, $59^{\circ} \mathrm{C}$ for $20 \mathrm{~s}$ and $70^{\circ} \mathrm{C}$ for $150 \mathrm{~s}$ followed. Amplification products from three independent PCRs were used to clone the $S^{\prime}$ end of the gene using a TA cloning kit (Invitrogen). Ligation products were transformed into $E$. coli strain $I N V \alpha \mathrm{F}^{\prime}$ and plated onto LB-agar containing X-Gal. Plasmid DNA was extracted from white colonies and the presence of a $2.0 \mathrm{~kb} \mathrm{M}$. byopneumoniae fragment was confirmed by restriction endonuclease digestion and agarose gel electrophoresis. A $2 \mathrm{~kb}$ fragment derived from each of three independent cloning experiments was sequenced (in both directions) initially using universal primers followed by a set of five forward and four reverse primers designed from the two adhesin sequences deposited in the database as described previously.

Cloning and sequencing of the reiterated repeat regions. PCR was used to amplify an $820 \mathrm{bp}$ DNA fragment encompassing RR1 and RR2 and was performed in a $50 \mu \mathrm{l}$ reaction mixture containing $200 \mu \mathrm{M}$ deoxyribonucleotide triphosphates, oligonucleotide primers RRF $\left(5^{\prime}\right.$ TCAGTATTCATTTGAAGCTA $3^{\prime}$ ) and RRR (5' CTCGATTAGTTCAACCTCTG $3^{\prime}$ ) at $200 \mathrm{nM}, 2$ units AmpliTaq Gold DNA polymerase (Perkin Elmer), $16 \mathrm{mM}\left(\mathrm{NH}_{4}\right)_{2} \mathrm{SO}_{4}, 67 \mathrm{mM}$ Tris/ $\mathrm{HCl}(\mathrm{pH} \mathrm{8.8)}$ and $4 \mathrm{mM} \mathrm{MgCl}$. The reaction mixtures were incubated at $94^{\circ} \mathrm{C}$ for $120 \mathrm{~s}$ for 1 cycle, followed by 25 cycles of denaturation at $94^{\circ} \mathrm{C}$ for $20 \mathrm{~s}$, primer annealing at $59^{\circ} \mathrm{C}$ for $20 \mathrm{~s}$ and extension at $70^{\circ} \mathrm{C}$ for $90 \mathrm{~s}$. A final cycle consisting of $94^{\circ} \mathrm{C}$ for $20 \mathrm{~s}, 59^{\circ} \mathrm{C}$ for $20 \mathrm{~s}$ and $70^{\circ} \mathrm{C}$ for $150 \mathrm{~s}$ followed. Three independent PCR reactions were performed for each of the six remaining strains of $M$. byopneumoniae and the amplification product from each PCR was cloned using the TA cloning kit as described above. DNA encoding the reiterated repeat regions was sequenced (as described above) in both directions initially using universal primers and with internal primers designed from sequence data generated from pAS1.

Southern blot analysis. EcoRI-digested M. byopneumoniae, $M$. byorbinis and M. flocculare genomic DNA were electrophoretically separated, blotted and probed using an $820 \mathrm{bp}$ PCR fragment (amplified using primers RRF and RRR) which was labelled by nick-translation according to standard procedures (Sambrook et al., 1989). Radiolabelled blots were stringently washed four times for $30-60 \mathrm{~min}$ at $65^{\circ} \mathrm{C}$. The first two washes consisted of a solution of $1 \mathrm{mM}$ EDTA, $40 \mathrm{mM}$ $\mathrm{NaHPO}_{4}$ and $5.0 \%$ SDS, pH 7.2, and the second two washes consisted of a solution of $1 \mathrm{mM}$ EDTA, $40 \mathrm{mM} \mathrm{NaHPO}$ and $1 \cdot 0 \%$ SDS, $\mathrm{pH} 7 \cdot 2$.

Statistical analysis. Statistical analysis on the $28 \mathrm{kDa}$ ELISA results was performed using the Tukey multiple comparisons test (Zar, 1984).

\section{RESULTS}

\section{Immunoscreening of DNA libraries and immunological characterization of a $28 \mathrm{kDa}$ $M$. hyopneumoniae strain $\mathrm{J}$ antigen}

EcoRI-digested genomic DNA from M. byopneumoniae strain J was ligated into each of three expression vectors pET23a, b and c. One clone, designated pAS1, expressed a $28 \mathrm{kDa}$ protein (in the presence of $10 \mathrm{mM}$ IPTG) reactive with porcine hyperimmune antiserum against $M$. byopneumoniae (data not shown). The $28 \mathrm{kDa}$ recombinant antigen was purified and used for the preparation of rabbit hyperimmune serum. Anti- $28 \mathrm{kDa}$ serum reacted strongly with whole-cell lysates of $E$. coli BL21(DE3)(pLysS) containing pAS1 (Fig. 1a) and also reacted with a $94 \mathrm{kDa}$ antigen in a whole-cell lysate of M. hyopneumoniae strain J in a Western blot (Fig. 1a). The antisera also reacted with a $30 \mathrm{kDa}$ protein in the whole-cell lysate of $M$. byopneumoniae strain J. Although the identity of this antigen remains unconfirmed it is likely to be a breakdown product of the $94 \mathrm{kDa}$ antigen (see trypsin studies). A $94 \mathrm{kDa}$ antigen, previously identified as a putative $M$. byopneumoniae-specific antigen (Scarman et al., 1997), was purified by preparative SDS-PAGE and was shown to react strongly with anti- $28 \mathrm{kDa}$ serum (Fig. $1 \mathrm{~b}$ ). Similarly, rabbit anti-94 kDa serum reacted strongly with the $28 \mathrm{kDa}$ recombinant antigen expressed from pAS1 (Fig. 1b). These data strongly suggested that the $28 \mathrm{kDa}$ antigen was derived from the $94 \mathrm{kDa} M$. byopneumoniae antigen.

\section{DNA and protein sequence analysis of pAS1}

Digestion of pAS1 with EcoRI revealed the presence of a single $2 \cdot 2 \mathrm{~kb} M$. byopneumoniae DNA insert (data not shown). DNA of pAS1 was used as a template to 
(a)

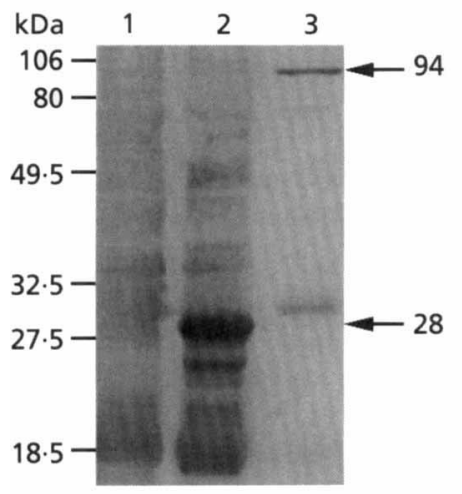

(b)

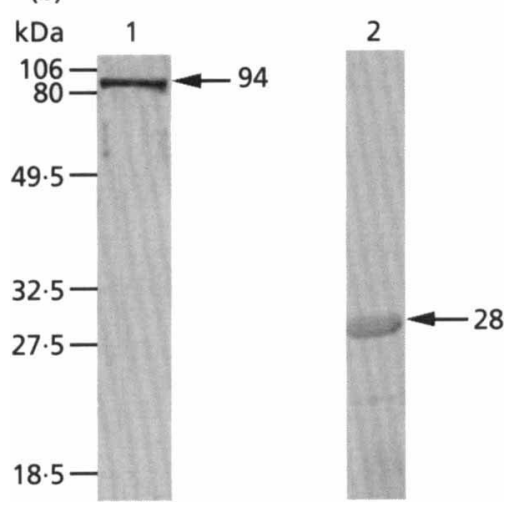

Fig. 1. Immunological characterization of the $28 \mathrm{kDa}$ antigen. Positions of molecular mass markers are given on the left. (a) Western blot of $E$. coli and $M$. hyopneumoniae whole-cell lysates separated in a $12 \%$ polyacrylamide gel reacted with anti-28 kDa serum. Lanes: 1 and 2 , whole-cell lysates of $E$. coli $B L 21(D E 3)$ (pLysS)(pAS1) grown in the absence (1) and presence (2) of $10 \mathrm{mM}$ IPTG; 3 , whole-cell lysate of $M$. hyopneumoniae strain J. (b) Western blot of a 12\% polyacrylamide gel of 491 Prep Cell-purified 94 kDa antigen (lane 1) and 28 kDa antigen (lane 2) reacted with anti-28 and anti-94 kDa sera, respectively.

sequence both strands of the $2 \cdot 2 \mathrm{~kb} \mathrm{M}$. hyopneumoniae EcoRI fragment. The fragment was shown to be $2194 \mathrm{nt}$ in length. Translation analysis revealed the presence of two ORFs (Fig. 2a). ORF1 was downstream of the T7 promoter of $\mathrm{pET} 23 \mathrm{c}$ and the translated product, comprising 556 aa, showed strong homology to two translation products deposited in databases (U27294 and U50901, 92 and $88 \%$, respectively); both sequences have been identified as M. hyopneumoniae adhesins (Hsu et al., 1997; King et al., 1996). From the deduced amino acid sequence, the predicted molecular mass of ORF1 was $62 \mathrm{kDa}$. The presence of two UGA codons at amino acid positions 546 and 766 in ORF1 precluded the expression of this protein in E. coli (Yamao et al., 1985). Amino acid analysis of the amino terminus of the $28 \mathrm{kDa}$ antigen expressed by pAS1 identified the sequence A-F-S-Y-K-L-E-Y-T-D-E-N-K-L-S immediately following a methionine residue at position 881 (Fig. 2b). A fortuitous, putative Shine-Dalgarno sequence was also identified 10 bases upstream from the start codon, indicating that the $28 \mathrm{kDa}$ antigen was expressed from this region of the sequence. A second ORF, ORF2, was identified immediately downstream from ORF1. No significant DNA or deduced protein sequence homology was identified using the ORF2 sequence in database searches. The presence of two regions of tandem repeats (RR1 and RR2) was also identified by sequence analysis of ORF1 (Fig. 2a). The first repeat region (RR1) consisted of repeating $15 \mathrm{bp}$ units, encoding the amino acid sequence $A(T)-K-P-E(V)-A(T)$, arranged as nine tandem repeats. The second (RR2) consisted of $30 \mathrm{bp}$ units, encoding the amino acid sequence G-A(E,S)-P$\mathrm{N}(\mathrm{S})-\mathrm{Q}-\mathrm{G}-\mathrm{K}-\mathrm{K}-\mathrm{A}-\mathrm{E}$, arranged as five tandem repeats.

\section{Cloning and DNA sequence analysis of the $5^{\prime}$ end of the ciliary adhesin gene}

To facilitate a comparison of the gene encoding the $94 \mathrm{kDa}$ M. hyopneumoniae antigen with genes encoding adhesins P97 (from strain 232) and Mhp1 (from strain $\mathrm{P} 5722$ ) the $5^{\prime}$ end of the gene encoding the $94 \mathrm{kDa}$ protein was amplified by PCR using primers $5^{\prime} \mathrm{F}$ and $3^{\prime} \mathrm{R}$ (Fig. 2a), cloned and sequenced three times. The predicted size of the $94 \mathrm{kDa}$ antigen based on the complete sequence was $123 \mathrm{kDa}$ which was similar to the calculated size reported for P97 and Mhp1 (124.9 and $124.2 \mathrm{kDa}$, respectively). Alignment of the predicted amino acid sequence of the $94 \mathrm{kDa}$ antigen with the amino acid sequences of $\mathrm{P} 97$ and Mhp1 revealed differences in the number of tandem repeats among different strains of $M$. byopneumoniae. The strain J adhesin contained nine copies of the 5-aa repeat and five copies of the 10-aa repeat whilst Mhp1 (strain P5722) had 12 copies of the 5 -aa repeat and five copies of the 10aa repeat (King et al., 1996). P97 (strain 232) had 15 copies of the 5-aa repeat and only four copies of the 10aa repeat (Hsu et al., 1997). The first 32 aa of the $94 \mathrm{kDa}$ antigen have features consistent with a prokaryotic signal sequence, including the presence of a cluster of positively charged amino acids $(K)$ followed by a stretch of hydrophobic residues ending with a signal peptidase II cleavage site (data not shown). The absence of a cysteine residue immediately after the cleavage site or anywhere within the deduced amino acid sequence discounted the possibility that the $94 \mathrm{kDa}$ antigen was a lipoprotein (Wieslander et al., 1992). Failure to detect sequence variation among three independent clones containing $5^{\prime}$ adhesin gene sequences and the absence of more than a single strongly hybridizing fragment in Southern blot experiments (see Fig. $5 \mathrm{~b}$ ) suggested that only a single copy of the adhesin gene resides in $M$. byopneumoniae strain J. Amino-terminal amino acid sequence data from purified P97 (Hsu et al., 1997) and Mhp1 (King et al., 1997) revealed that the first 195 aa had been removed and suggested that the ciliary adhesin was produced from a $124.5 \mathrm{kDa}$ precursor which was subsequently processed to $102 \mathrm{kDa}$ by proteolytic cleavage. Western blots of whole-cell lysates of different strains of $M$. hyopneumoniae reacted with anti-94 kDa serum (Fig. 3) identified a major immunogen ranging from 94 to $97 \mathrm{kDa}$ (allowing for differences in the 
(a)

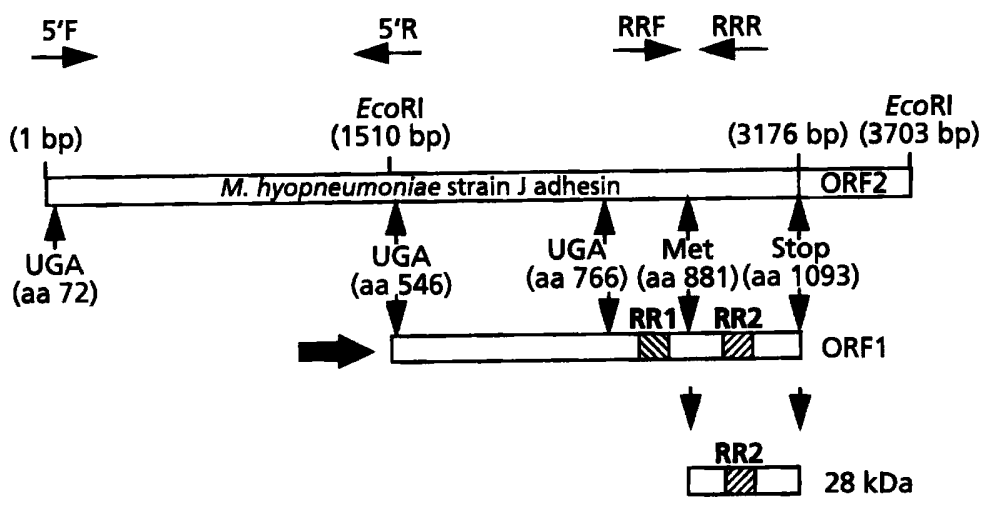

(b)

SD $\quad M \quad$\begin{tabular}{|llllllllllllllllll}
$A$ & $F$ & $S$ & $Y$ & $K$ & $L$ & $E$ & $Y$ & $T$ & $D$ & $E$ & $N$ & $K$ & $I$ & $S$ & $I$ & $K$
\end{tabular} CCAAAAGAGACTATTTCCCAATGGCTTTTAGTTATAAATTAGAATATACTGACGAAAATAAATTAAGCCTAAAA
Fig. 2. Genetic map of the $M$. hyopneumoniae strain J adhesin. (a) Diagrammatic representation showing the oligonucleotide primers used to amplify the $5^{\prime}$ end of the strain $J$ adhesin ( $5^{\prime} F$ and $5^{\prime} R$ ) and a fragment spanning the repeat regions (RRF and RRR). Translation of a $2 \cdot 2 \mathrm{~kb}$ insert ECORI fragment identified putative ORFs (ORF1 and ORF2). ORF1 encoded the 3' region of the adhesin. UGA codons which specify a translational stop in $E$. coli but a tryptophan in mycoplasmas were located at amino acid positions 72,546 and 766 . The filled arrow indicates the T7 promoter from which a protein of $28 \mathrm{kDa}$ is expressed from the methionine start at amino acid position 881 and translational stop at position 1093. The $3^{\prime}$ end of the adhesin contained two repeat regions (RR1 and RR2; hatched), the first with 5 aa repeated nine times and the second with 10 aa repeated five times. (b) The amino-terminal sequence of the $28 \mathrm{kDa}$ protein expressed from ORF1. The amino acids amino-terminally microsequenced from the $28 \mathrm{kDa}$ protein are boxed, the methionine start directly upstream is shown in bold and the putative Shine-Dalgarno consensus sequence (SD) identified a further $10 \mathrm{bp}$ upstream is underlined. number of repeats in RR1 and RR2), suggesting that this processing event occurs in all strains of $M$. byopneumoniae so far examined.

\section{Surface location of the $94 \mathrm{kDa}$ antigen}

Zhang et al. (1995) demonstrated the presence of P97 on the surface of $M$. hyopneumoniae using immunoelectron microscopy. To demonstrate the surface location of the $94 \mathrm{kDa}$ antigen in $M$. byopneumoniae strain J, whole $M$. hyopneumoniae cells were resuspended in PBS and digested with trypsin at concentrations of $0,0 \cdot 1,0 \cdot 3,0 \cdot 5$, $1,2,3$ and $5 \mu \mathrm{g} \mathrm{ml}^{-1}$. Immunoblots of proteins of trypsin-treated whole $M$. hyopneumoniae cells probed with anti-28 kDa serum showed a steady decline in the detectable levels of the $94 \mathrm{kDa}$ antigen at trypsin concentrations ranging from 0.1 to $1.0 \mu \mathrm{g} \mathrm{ml}^{-1}$ (Fig. 4). The $94 \mathrm{kDa}$ antigen was undetectable in $M$. byopneumoniae treated with more than $2.0 \mu \mathrm{g} \mathrm{ml}^{-1}$ trypsin for $15 \mathrm{~min}$, suggesting that the $94 \mathrm{kDa}$ antigen and the $28 \mathrm{kDa}$ carboxy-terminal portion of this antigen reside on the surface of intact mycoplasmas. Cell integrity was demonstrated by reprobing the Western blot with rabbit antiserum raised to a purified preparation of recombinant lactate dehydrogenase from $M$. byopneumoniae (A. L. Scarman, G. J. Eamens \& S. P. Djordjevic, unpublished results). Lactate dehydrogenase $(36 \mathrm{kDa})$ has been shown to reside in the cytosol in M. byopneumoniae (Strasser et al., 1991). An immunoreactive antigen of equal staining intensity and with a molecular mass of $36 \mathrm{kDa}$ was observed in all preparations of trypsin-treated whole $M$. byopneumoniae cells confirming that trypsin did not cause cell lysis (Fig. 4).

\section{Immunogenicity of the $\mathbf{2 8} \mathbf{~ k D a}$ antigen}

M. byopneumoniae-free pigs were experimentally infected with the virulent Beaufort strain of $M$. byopneumoniae as described previously (Fagan et al., 1996). Serum samples from six pigs, three taken prior to inoculation, were used to monitor the humoral immune response against the purified $28 \mathrm{kDa}$ antigen. Although the temporal immune response varied between animals, antibodies which recognized the carboxy-terminal $28 \mathrm{kDa}$ portion of the $94 \mathrm{kDa}$ adhesin could be detected soon after challenge, becoming statistically significant $(P<0.05) 7$ weeks after challenge (data not shown).

\section{Strain variation in the adhesin antigen}

Rabbit anti-28 and anti-94 kDa sera were used to probe identical Western blots of whole-cell lysates of seven $M$. byopneumoniae strains from different geographic locations as well as four strains of $M$. byorbinis and a single type strain of $M$. flocculare. The anti-28 kDa serum primarily reacted with a single antigen which varied in molecular mass between 94 and $97 \mathrm{kDa}$ in all seven $M$. byopneumoniae strains (Fig. 3a). The presence of more than one immunoreactive band can be observed for strains $\mathrm{J}(30 \mathrm{kDa}$ as seen previously) and $\mathrm{YZ}$ (approx. $78 \mathrm{kDa}$ ). Strain $\mathrm{C} 1735 / 2$ had the least immunoreactive band of all seven $M$. byopneumoniae strains. Very weak cross-reactivity was observed with the whole-cell lysate of $M$. flocculare type strain Ms42, identifying two immunoreactive bands of 97 and $85 \mathrm{kDa}$ (Fig. 3a). No cross-reactivity was observed with the whole-cell lysates of the four M. byorhinis strains used in this study. 
(a)

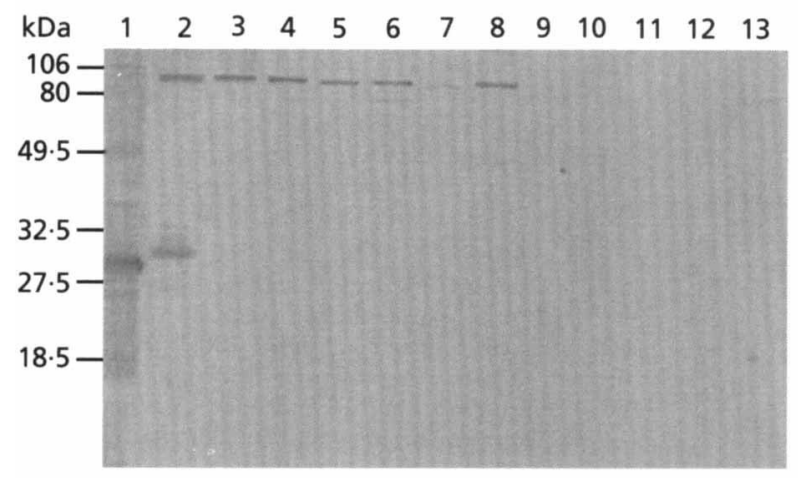

(b)

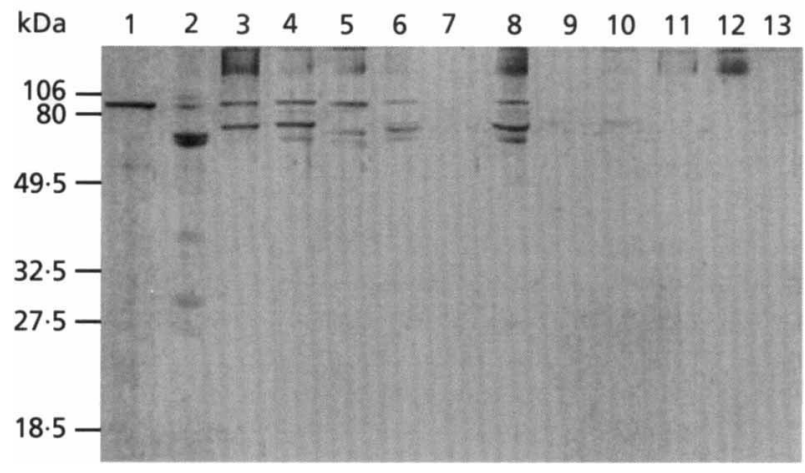

Fig. 3. Western blot analysis of 12 porcine mycoplasma strains. Whole-cell lysates were resolved in a $12 \%$ polyacrylamide gel for reaction with (a) anti-28 and (b) anti-94 kDa sera. Positions of molecular mass markers are given on the left. Lanes: $1, E$. coli BL21(DE3)(pLysS)(pAS1) grown in the presence of $10 \mathrm{mM}$ IPTG in (a) and column-purified $94 \mathrm{kDa}$ antigen in (b); $2-8, \mathrm{M}$. hyopneumoniae strains J, 232, Beaufort, Sue, YZ, C1735/2 and OMZ407, respectively; 9-12, M. hyorhinis strains field strain 1, GDL, BTS-7 and field strain 2; 13, M. flocculare type strain Ms42.

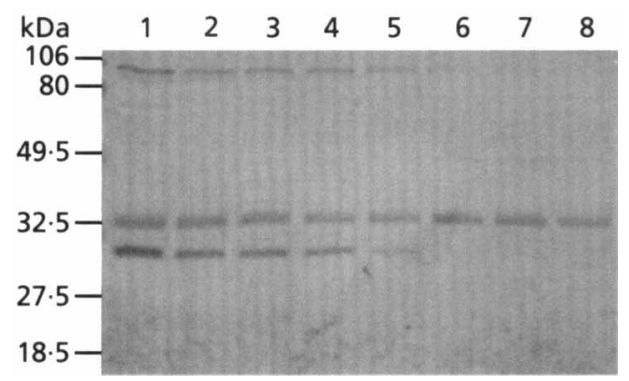

Fig. 4. Western blot showing cell lysates of $M$. hyopneumoniae whole cells treated with $0,0.1,0.3,0.5,1,2,3$ and $5 \mu \mathrm{g}$ trypsin $\mathrm{ml}^{-1}$ (lanes 1-8, respectively) separated in a $12 \%$ polyacrylamide gel and reacted with anti-28 and anti-36 kDa sera. Anti-36 kDa serum (raised against lactate dehydrogenase) failed to show a decrease in staining intensity at all trypsin concentrations, confirming cell integrity. Positions of molecular mass markers are given on the left.

In addition to detecting a $94-97 \mathrm{kDa}$ antigen in wholecell lysates of all strains of $M$. byopneumoniae (except strain $\mathrm{C} 1735 / 2$ ), rabbit anti-94 $\mathrm{kDa}$ serum identified several other $M$. byopneumoniae antigens ranging in molecular mass from 65 to $80 \mathrm{kDa}$ (Fig. 3b). These antigen profiles are very similar to those described by Zhang et al. (1995) using mAbs raised against the P97 adhesin. Faintly reacting high molecular mass antigens were also observed in whole-cell lysates of two of the four M. hyorhinis strains (type strains GDL and BTS-7) and M. flocculare type strain Ms42 (Fig. 3b).

\section{PCR and Southern blot analysis}

PCR primers RRF and RRR (see Fig. 2a) amplified an 820 bp fragment spanning RR1 and RR2 using template DNA from $M$. hyopneumoniae strain J. When used to amplify the same fragment from genomic DNA isolated from six other strains of $M$. byopneumoniae, a single amplification product ranging in size from 750 to $900 \mathrm{bp}$ was observed (Fig. 5a). PCR products were not observed using genomic DNA isolated from four different strains of $M$. hyorbinis or a single type strain of $M$. flocculare (Fig. 5a), suggesting that the $94 \mathrm{kDa}$ adhesin gene was not present in the genomes of these two phylogenetically related species which inhabit the respiratory tract of pigs (Stemke et al., 1992). This result was confirmed by the failure of the 820 bp PCR fragment to hybridize under stringent conditions to EcoRI-restricted genomic DNA of these Mycoplasma species (Fig. 5b). A single, strongly reactive EcoRI fragment ranging in size from 2.15 to $2.30 \mathrm{~kb}$ (Fig. 5b) hybridized with the radiolabelled 820 bp PCR fragment, suggesting that different strains of $M$. byopneumoniae may produce an adhesin with variable numbers of oligopeptide repeats within RR1 and RR2. Several weakly hybridizing EcoRI fragments were observed in Southern blot profiles of $M$. byopneumoniae strains 232, YZ, Sue and C1735/2 and a single extremely weak fragment in the strain J profile (data not shown). No weakly hybridizing fragments were observed in the EcoRI profiles of $M$. byopneumoniae strains Beaufort and OMZ407. Although whole-cell lysates of strain C1735/2 displayed a poorly immunoreactive antigen when reacted with anti- 28 and $94 \mathrm{kDa}$ sera, a strong hybridization signal (to a $2 \cdot 15 \mathrm{~kb}$ EcoRI fragment) was observed using the 820 bp probe (Fig. 5b). The stronger hybridization signals with EcoRI fragments from 232 and $\mathrm{C} 1735 / 2$ were not correlated with a higher concentration of loaded DNA. This was determined by comparing the intensity of ethidium bromide staining in the agarose gel containing all seven strains of M. hyopneumoniae DNA used for Southern blotting (data not shown). The possibility that more than one copy of the ciliary adhesin gene may reside in these two strains would require that DNA sequences containing the EcoRI restriction site in ORF2 also be duplicated.

\section{Comparison of deduced amino acid sequences spanning RR1 and RR2 from geographically diverse strains of $M$. hyopneumoniae}

DNA sequence analysis of cloned PCR fragments comprising a region of DNA encoding RR1 and RR2 
(a)

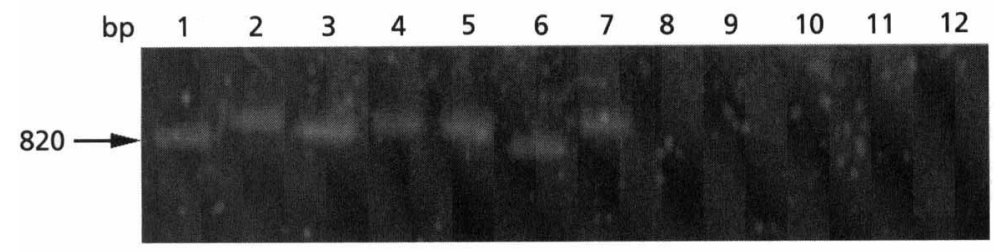

Fig. 5. PCR and Southern blot analysis of genomic DNA from 12 porcine Mycoplasma strains. (a) PCR products (visualized on a $1.5 \%$ agarose gel with ethidium bromide staining) of an amplification using primers RRF and RRR which flank the area encoding repeat regions 1 and 2. (b) Southern blot of EcoRI-digested genomic DNA (transferred from a $1 \%$ agarose gel) probed with an 820 bp fragment spanning RR1 and RR2 amplified from $M$. hyopneumoniae strain J DNA using primers RRF and RRR. Lanes: 1-7, $M$. hyopneumoniae strains J, 232, Beaufort, Sue, YZ, C1735/2 and OMZ407, respectively; 8-11, $M$. hyorhinis strains field strain 1, GDL, BTS-7 and field strain 2; 12, $M$. flocculare type strain Ms42.

from geographically diverse strains of $M$. byopneumoniae were compared (Fig. 6). The deduced amino acid sequences showed considerable variation, particularly in the number of tandem 5-aa repeats in RR1. Australian strains Beaufort and OMZ407 possessed 15 tandem copies of the 5-aa repeat in RR1 and three tandem copies of the 10-aa repeat in RR2. Australian strain Sue possessed 12 tandem copies of the 5-aa repeat in RR1 and four tandem copies of the 10-aa repeat in RR2. French strain YZ possessed 11 tandem copies of the 5-aa repeat and four tandem copies of the 10 -aa repeat in RR1 and RR2, respectively. Finally, Australian isolate $\mathrm{C} 1735 / 2$ possessed the fewest number of tandem copies (eight) of the 5-aa repeat in RR1 and had four tandem copies of the 10-aa repeat in RR2 (Fig. 6).

\section{DISCUSSION}

Evidence that an immunoreactive $94 \mathrm{kDa} M$. byopneumoniae strain J antigen is a ciliary adhesin is based on the following observations: (i) the gene encoding the $94 \mathrm{kDa}$ antigen shows strong homology (greater than $90 \%$ ) to two M. byopneumoniae ciliary adhesin gene sequences deposited in GenBank, (ii) the $94 \mathrm{kDa}$ antigen is surface-accessible and (iii) anti-94 $\mathrm{kDa}$ serum reacts with several antigens ranging predominantly from 65 to $97 \mathrm{kDa}$, displaying antigenic size variation patterns similar to those described by Zhang et al. (1995) using mAbs against the P97 adhesin. We have demonstrated that the $94 \mathrm{kDa}$ antigen possesses repetitive proline-rich sequences in the carboxy terminus of the protein. The $94 \mathrm{kDa}$ antigen from strain $\mathrm{J}$ had fewer 5 -aa repeats in RR1 (nine repeats) compared with P97 which is expressed in a lower-passage strain (232) of $M$. byopneumoniae (15 repeats). Mhp1 had 12 repeats (RR1) but is derived from M. hyopneumoniae strain P5722 of unknown virulence. Strain 232 also had one less copy of the 10-aa repeat of RR2. Except for the repeat regions and three deletions (aa 890-893, 1021-1030 and 1084) in strain 232 , the deduced amino acid sequences of all three strains were very similar $(93.3$ and $95.7 \%$ homology, respectively).

The presence of a ciliary adhesin gene in the highly passaged, avirulent strain J of $M$. byopneumoniae with significant homology to adhesin gene sequences from a low-passage, virulent strain of this pathogen encouraged us to investigate if differences in the number of reiterated repeat regions also existed amongst a panel of $M$. byopneumoniae strains from different geographic localities. Whilst the number of repeats in RR2 remained between 3 and 4 copies, the number of repeats in RR1 ranged from 8 to 15 . The presence of a transposon insertion (Tn1000) in RR2 (residue 1004) in P97 failed to abrogate either ciliary binding or diminish the ability of mAb F1B6 to bind to P97 (Hsu et al., 1997), strongly suggesting that RR2 is not essential for these functions. Although the exact nature of the epitope recognized by mAb F1B6 has not been determined, the ability of a Tn1000 insertion 109 residues upstream of the beginning of RR1 (residue 704) to abrogate ciliary and mAb binding defines the biologically important region(s) of the molecule between these two transposon insertion sites spanning 300 residues (aa 704-1004) in the carboxy terminus of P97. Although RR1 only comprises approximately $25 \%$ of the amino acids spanning the two transposon insertion sites, proline-rich repeats (PRRs, which reside in RR1 and RR2) are often highly immunogenic (Williamson, 1994), suggesting that RR1 may comprise an epitope(s) recognized by mAb F1B6 crucial for ciliary binding. Although RR2 does not appear to be essential for ciliary binding, it has been retained in all strains of $M$. byopneumoniae so far examined and does not undergo much variation in the number of repeats (3-5 copies). Results described in this study clearly demonstrate that porcine antibodies are raised to RR2 during experimental infection with $M$. 

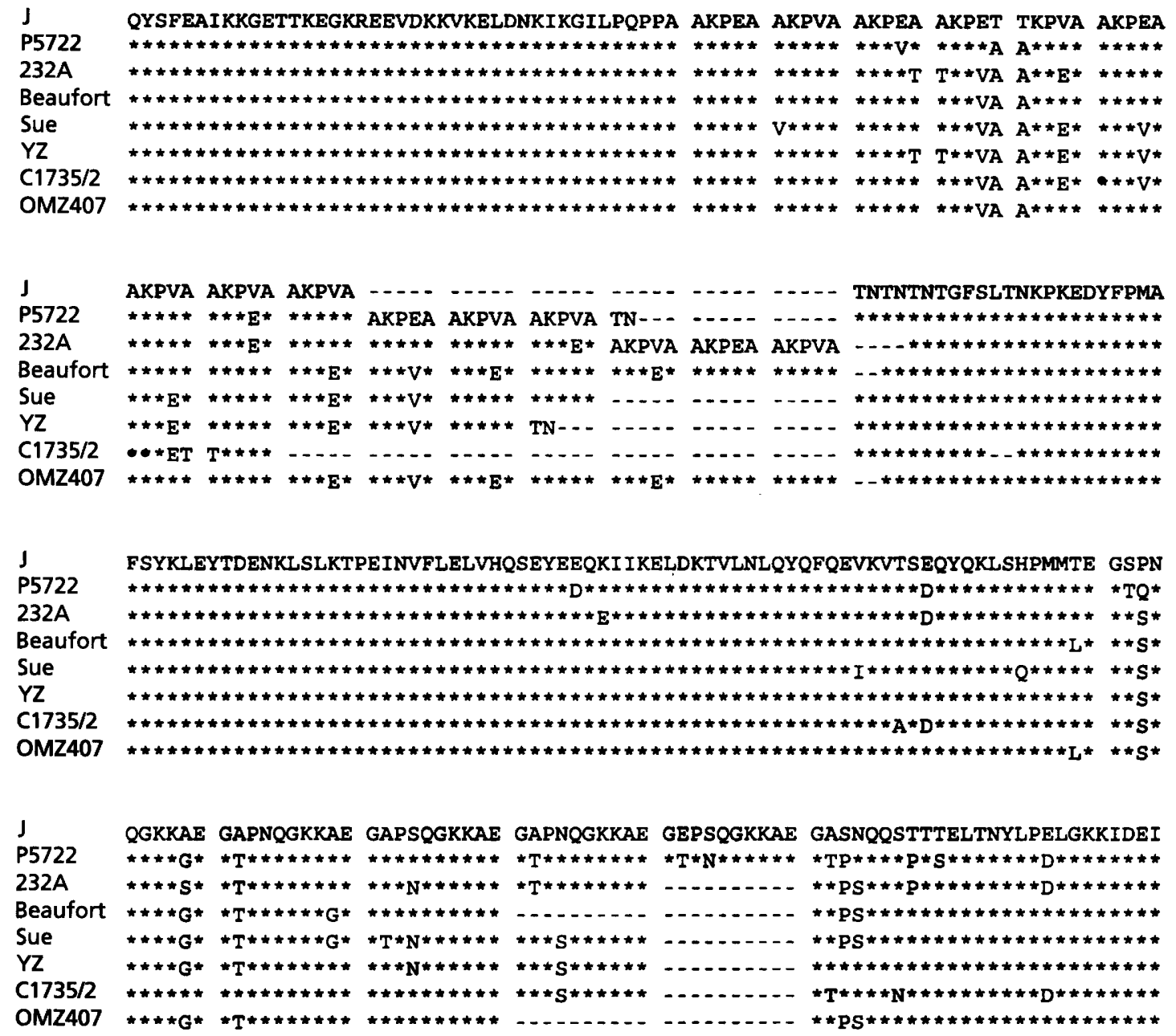

\begin{tabular}{|c|c|c|}
\hline J & 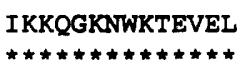 & \\
\hline $\begin{array}{l}232 A \\
\text { Beaufort } \\
\text { Sue } \\
\text { YZ } \\
\text { C1735/2 } \\
\text { OMZ407 }\end{array}$ & 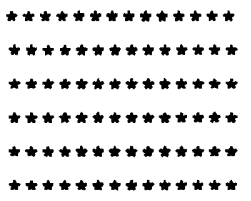 & $\begin{array}{l}\text { Fig. 6. Predicted amino acid sequences of PCR amplification } \\
\text { products spanning RR1 and RR2 from eight strains of } \\
M \text {. hyopneumoniae originating from different geographic } \\
\text { localities. Repeat regions are spaced as oligopeptide units with } \\
\text { homologous amino acids denoted by an asterisk and deletions } \\
\text { represented by a dash. }\end{array}$ \\
\hline
\end{tabular}

byopneumoniae, tempting speculation that $\mathrm{RR} 2 \mathrm{might}$ serve as an immune decoy directing the host humoral immune response to a non-essential portion of the ciliary adhesin. Deletion or transposon mutagenic analyses rather than site-directed mutagenic approaches may be required to precisely map biologically essential portion(s) of the molecule since interactions involving PRRs are dependent upon multiple weak binding sites rather than lock and key binding (Williamson, 1994). Further studies are required to investigate the role of RR1 and RR2 in ciliary binding.

Studies by King et al. (1996) suggested that Mhp1 may be duplicated in the genome of $M$. byopneumoniae strain P5722. Similarly, Hsu et al. (1997) suggested that P97 was duplicated in M. hyopneumoniae strain 232A.
Using an 820 bp hybridization probe spanning RR1 and RR2, a single strongly hybridizing fragment ranging from $2 \cdot 15$ to $2 \cdot 3 \mathrm{~kb}$ was observed on Southern blots of EcoRI digests of the seven strains of $M$. byopneumoniae DNA used in this study (Fig. 5b). Although several weakly hybridizing bands were observed with DNA from strains 232, YZ, Sue and C1735/2, suggesting that multiple copies of RR1 and/or RR2 may be present, none was observed in Australian isolates Beaufort and OMZ407 and only one extremely faint band was observed in the EcoRI digest of M. byopneumoniae strain J. If the adhesin gene is duplicated in the genomes of $M$. hyopneumoniae with differences in the number of repeats in RR1 and RR2, our PCR cloning strategy should have detected them. These data provide circumstantial evidence that ciliary adhesin genes with a 
variable number of repeat regions do not exist as multiple copies in $M$. hyopneumoniae. However, it is feasible that less homologous DNA fragments, including RR1 and/or RR2, may be duplicated elsewhere in the genome.

The pattern of multiple antigens $(65-97 \mathrm{kDa})$ on Western blots of whole-cell lysates of $M$. hyopneumoniae reacting with anti-94 $\mathrm{kDa}$ serum has similarity to immunoblot profiles described using $\mathrm{mAbs}$ raised against the P97 adhesin (Zhang et al., 1995; Hsu et al., 1997). Differences in the number of repeats in RR1 and RR2 is insufficient to account for this complex antigen profile. Anti- $28 \mathrm{kDa}$ serum predominantly recognized a single antigen of $94-97 \mathrm{kDa}$ in whole-cell lysates of the seven $M$. byopneumoniae strains which could be explained by differences in the number of repeats in RR1 and RR2. King et al. (1996) speculated that multiple immunoreactive antigens may be cleavage products of the mature protein. Asp-Pro bonds undergo cleavage under mildly acid conditions (Kyte, 1995) and cleavage occurs during the processing of samples for SDS-PAGE giving rise to a ladder pattern in immunoblots (Wästfelt et al., 1996). Several Asp-Pro peptide bonds (aa 107-108, 204-205, 1068-1069) are present in the deduced amino acid sequence of the $94 \mathrm{kDa}$ protein. However, the molecular masses of such cleavage products are inconsistent with the immunoblot profile generated using anti-94 kDa serum and the predicted cleavage products should also be reactive with anti- $28 \mathrm{kDa}$ serum. Size heterogeneity may result from premature translation or proteolytic cleavage and the former of these two possibilities would be consistent with the immunoblot profiles observed with the anti- $28 \mathrm{kDa}$ serum. Interestingly, whole-cell lysates of $M$. byopneumoniae strain C1735/2 were poorly immunoreactive with anti94 and anti-28 kDa sera, although faintly reactive bands were observed. Whole-cell lysates of strain C1735/2 are also poorly immunoreactive with porcine hyperimmune antiserum raised against $\mathrm{J}$ and Beaufort strains of $M$. hyopneumoniae (Scarman et al., 1997). Cryptic mycoplasmal epitopes which fail to react with mAbs have been described in several Mycoplasma species and can be explained by the ability of surface antigens to undergo phase variation (Rosengarten \& Yogev, 1996). However, since hyperimmune sera typically recognize a plethora of epitopes it is unusual for whole-cell lysates to react poorly with homologous hyperimmune sera, although others have reported such a phenomenon (Avakian et al., 1991).

Like the extracellular porcine pathogen $M$. byopneumoniae, Mycoplasma pneumoniae is an extracellular pathogen which specifically adheres to the ciliated epithelial lining of the human respiratory tract. It requires adhesion to host-cell receptors for colonization and subsequent development of disease. A surface protein of $M$. pneumoniae containing PRRs, displaying size polymorphism and possessing an R-G-D sequence has been identified and designated P65 (Proft $e t$ al., 1995). P65 has not yet been implicated in binding host cells but its exclusive localization in the Triton X- 100-insoluble fraction makes it a likely candidate. The amino-terminal portion of P65 comprises two PRR regions that form a proline-rich acidic domain. The repeats (D-P-N-A-Y and D-P-N-Q-A-Y) are responsible for the observed size polymorphism in immunoblots of whole-cell lysates of two different strains of $M$. pneumoniae, one a clinical isolate and the other a highpassage laboratory strain. The high-passage strain $\mathrm{FH}$ of $M$. pneumoniae contained 12 D-P-N-A-Y repeats whilst the clinical isolate contained only nine copies.

Virulence in mycoplasmas has been shown to be attenuated by successive passage in laboratory media (Collier et al., 1985). Zhang et al. (1994a) demonstrated that M. byopneumoniae strain 232 L127 showed decreased adherence to porcine cilia with increasing passage in Friis medium, noting a significant reduction $(P<0.01)$ in adherence after 50 passages. $M$. byopneumoniae strains maintained in Friis medium with minimal passage bind relatively strongly to porcine cilia compared to the high-passage strain J (DeBey \& Ross, 1994; Zhang et al., 1995). Furthermore, low-passage strains of $M$. byopneumoniae are pathogenic for pigs whilst the high-passage strain $\mathrm{J}$ is unable to induce pneumonia or to be re-isolated from the lungs of animals after challenge (Zielinski \& Ross, 1990; Zielinski et al., 1993). All strains of $M$. byopneumoniae so far characterized (except C1735/2) revealed a greater number of repeats in RR1 compared to the high-passage, avirulent strain J. Although the ability of the four Australian strains (Beaufort, Sue, OMZ407 and C1735/2) described in this study to bind to porcine cilia has not been determined, it is likely that they demonstrate binding activity since all were recovered from lung lesions and have undergone minimal passage in vitro.

Repetitive regions within DNA have been described in a wide range of organisms and are known to be active sites for homologous recombination or slipped-strand mispairing (Albertini et al., 1982; Petes \& Hill, 1988; Wren, 1991; Dybvig \& Voelker, 1996). Intragenic recombination amongst tandem repeats in a single gene in Xanthomonas campestris pv. malvacearum provide a mechanism for the evolution of new host specificities (Yang \& Gabriel, 1995). Surface proteins displaying reiterated repeats are increasingly being reported in mycoplasmas (Proft et al., 1995; Zheng et al., 1995; Zhang \& Wise 1996) and phylogenetically related Grampositive bacteria (Wren, 1991; Wästfelt et al., 1996). The $\mathrm{MB}$ antigen from Ureaplasma urealyticum contains 42.5 repeats of a 6-aa motif G-K-E-Q-P-A which reside in the carboxy-terminal portion of the molecule, is antigenic and surface-exposed and is responsible for antigenic size variation. Furthermore, it has been postulated that different antigen sizes may be associated with a specific pathological manifestation (Zheng et al., 1995).

Proline is present in both repeats found in RR1 and RR2 in the M. byopneumoniae adhesin. PRRs within proteins are often found as multiple tandem repeats of variable length in both prokaryotes and eukaryotes and are usually highly immunogenic (Williamson, 1994). Many 
proline-rich sequences have been demonstrated to be involved in binding processes, a large number of which are located on the cell surface. In particular, bacterial outer-membrane proteins associated with transport functions, binding cytoskeletal proteins, binding peptidoglycan and intracellular signalling have been demonstrated to contain PRRs critical in performing such tasks (Williamson, 1994, and references therein). The involvement of PRRs in binding occurs in a nonstoichiometric, but functionally important way and has a unique ability to bind rapidly and tightly to receptor molecules (Williamson, 1994). The bulkiness of the proline side chain and the replacement of the amide proton by a methylene group disrupts $\alpha$-helix and $\beta$ sheet formation. The relatively large proportion of charged amino acids in the ciliary adhesin and the propensity for proline-rich peptides to be highly soluble in water provides an explanation for the partitioning of the adhesin to the aqueous phase during extraction with Triton X-114 (Williamson, 1994; Zhang et al., 1995). An R-G-D sequence, implicated in integrin binding in a broad range of viruses, bacteria and eukaryote parasites, is often found in conjunction with PRRs (Leininger et al., 1991). Although a search of the $94 \mathrm{kDa}, \mathrm{P} 97$ and Mhp1 adhesins failed to identify an R-G-D sequence, two integrin-binding L-E-T sequence motifs which recognize $\alpha_{1} \beta_{2}$ integrins (Ruoslahti, 1996) were located at positions $618-620$ and $630-632$ in the deduced amino acid sequences of the $94 \mathrm{kDa}, \mathrm{P} 97$ and Mhp1 adhesins. In addition, two R-X-X-X-D sequence motifs, which recognize $\alpha_{1} \beta_{1}$ integrins (Ruoslahti, 1996), were located at positions 221-225 and 791-795 in the deduced amino acid sequences of the $94 \mathrm{kDa}, \mathrm{P} 97$ and Mhp1 adhesins. Site-directed mutagenesis studies would be useful to determine if these sequence motifs are involved in ciliary adhesion.

Proline-rich sequences are often accompanied by a relatively high prevalence of glutamine. Glutamine is present in the reiterated repeats comprising RR2 in the deduced amino acid sequences of the $94 \mathrm{kDa}, \mathrm{P} 97$ and Mhp1 adhesins. In addition, 4 of the 5 aa residues immediately $5^{\prime}$ to RR1 (P-Q-P-P-A) are either proline or glutamine moieties. Glutamine is the second most likely residue (proline being the first) to appear in a polyproline helix segment in globular proteins (Adzhubei \& Sternberg, 1993). A sequence of four or more consecutive prolines adopts a conformation in solution known as a polyproline II helix making an extended conformationally restricted polypeptide chain (Adzhubei \& Sternberg, 1993). However, polyproline II helices typically comprise repetitive short proline-rich sequences of 2-3 aa such as $(X-P-Y)_{n}$. RR1 and RR2 comprise tandem repeats each containing 5 and $10 \mathrm{aa}$, respectively and these sequences are typically involved in protein-protein binding. The restricted mobility afforded by such structures enhances binding ability by reducing the unfavourable entropy loss of peptides on binding (Williamson, 1994).

Earlier studies by Young et al. $(1990,1992)$ reported that P97 was expressed during $M$. byopneumoniae infection and that an $\operatorname{IgG}$ and $\operatorname{IgA}$ immune response was elicited against it in the respiratory tract of contact-exposed pigs 35-60 d earlier than other M. byopneumoniae antigens. Pigs experimentally infected with a virulent strain of $M$. byopneumoniae mounted a humoral immune response against the $28 \mathrm{kDa}$ recombinant antigen immediately after challenge and antibody concentrations continued to rise for at least 7 weeks. Whilst immunodominant epitopes appear to be present in the carboxy-terminal portion of the $94 \mathrm{kDa}$ antigen, which encompasses RR1 and RR2, further studies are required to identify the crucial part(s) of the molecule involved in attachment and to determine which are capable of eliciting a protective immune response.

\section{ACKNOWLEDGEMENTS}

The assistance provided by G. J. Eamens for the immunization, bleeding and euthanasia of experimental rabbits and in provision of sera from experimentally challenged pigs is gratefully acknowledged. J. Wilton is supported by an Australian Postgraduate (Industry) Award in conjunction with Bunge Meat Industries.

\section{REFERENCES}

Adzhubei, A. A. \& Sternberg, M. J. E. (1993). Left-handed polyproline II helices commonly occur in globular proteins. J Mol Biol 229, 472-493.

Albertini, A. M., Hofer, M., Calos, P. \& Miller, J. H. (1982). On the formation of spontaneous deletions: the importance of short sequence homologies in the generation of large deletions. Cell 29, 319-328.

Avakian, A. P., Kleven, S. H. \& Ley, D. H. (1991). Comparison of Mycoplasma gallisepticum strains and identification of immunogenic integral membrane proteins with Triton X-114 by immunoblotting. Vet Microbiol 29, 319-328.

Burnette, W. N. (1981). Western blotting: electrophoretic transfer of proteins from sodium dodecyl sulfate-polyacrylamide gels to unmodified nitrocellulose and radiographic detection with antibody and radioiodinated protein A. Anal Biochem 112, 195-203.

Clark, L. K., Armstrong, C. H., Freeman, M. J., Scheidt, A. B., Sands-Freeman, L. \& Knox, K. (1991). Investigating the transmission of Mycoplasma byopneumoniae in a swine herd with enzootic pneumonia. Vet Med 86, 543-550.

Collier, A. M., Hu, P. C. \& Clyde, W. A. (1985). The changing pathogenicity of Mycoplasma pneumoniae with passage in vitro correlates with virulence. Diagn Microbiol Infect Dis 3, 321-328.

DeBey, M. C. \& Ross, R. F. (1994). Ciliostasis and loss of cilia induced by Mycoplasma byopneumoniae in porcine tracheal organ cultures. Infect Immun 62, 5312-5318.

Djordjevic, S. P., Eamens, G. J., Romalis, L. F. \& Saunders, M. M. (1994). An improved enzyme-linked immunosorbent assay (ELISA) for the detection of serum antibodies against Mycoplasma byopneumoniae. Vet Microbiol 39, 261-274.

Djordjevic, S. P., Eamens, G. J., Romalis, L. F., Nicholls, P. J., Taylor, V. \& Chin, J. (1997). Serum and mucosal antibody responses and protection in pigs vaccinated against Mycoplasma 
byopneumoniae with vaccines containing a denatured membrane antigen pool and adjuvant. Aust Vet J 75, 504-511.

Dybvig, K. \& Voelker, L. L. (1996). Molecular biology of mycoplasmas. Annu Rev Microbiol 50, 25-57.

Etheridge, J. R., Cottew, G. S. \& Lloyd, L. C. (1979). Isolation of Mycoplasma hyopneumoniae from lesions in experimentally infected pigs. Aust Vet J 55, 356-359.

Fagan, P. K., Djordjevic, S. P., Eamens, G. J., Chin, J. \& Walker, M. J. (1996). Molecular characterisation of a ribonucleotide reductase ( $n r d F$ ) gene fragment of Mycoplasma hyopneumoniae and assessment of the recombinant product as an experimental vaccine for enzootic pneumonia. Infect Immun 64, 1014-1018.

Haldimann, A., Nicolet, J. \& Frey, J. (1993). DNA sequence determination and biochemical analysis of the immunogenic protein $\mathrm{P} 36$, the lactate dehydrogenase (LDH) of Mycoplasma byopneumoniae. J Gen Microbiol 139, 317-323.

Hsu, T., Artiushin, S. \& Minion, F. C. (1997). Cloning and functional analysis of the P97 swine cilium adhesin gene of Mycoplasma byopneumoniae. J Bacteriol 179, 1317-1323.

King, K. W., Faulds, D. H., Rosey, E. L. \& Yancey, R. J. (1997). Characterization of the gene encoding Mhp1 from Mycoplasma byopneumoniae and examination of Mhp1's vaccine potential. Vaccine 15, 25-35.

Klinkert, M.-Q., Herrmann, R. \& Schaller, H. (1985). Surface proteins of Mycoplasma byopneumoniae identified from an Escherichia coli expression plasmid library. Infect Immun 49, 329-335.

Kyte, J. (1995). Sequences of polymers. In Structure in Protein Chemistry, pp. 71-102. London \& New York: Garland Publishing.

Laemmli, U. K. (1970). Cleavage of structural proteins during the assembly of the head of bacteriophage T4. Nature 227, 680-685.

Leininger, E., Roberts, M., Kenimer, J. G., Charles, I. G., Fairweather, N., Novotny, P. \& Brennan, M. J. (1991). Pertactin, an Arg-Gly-Asp-containing Bortedella pertussis surface protein that promotes adherence of mammalian cells. Proc Natl Acad Sci USA 88, 345-349.

Petes, T. D. \& Hill, C. W. (1988). Recombination between repeated genes in microorganisms. Annu Rev Genet 22, 147-168.

Proft, T., Helmut, H., Layh-Schmitt, G. \& Herrmann, R. (1995). The proline-rich P65 protein of Mycoplasma pneumoniae is a component of the Triton-X-100-insoluble fraction and exhibits size polymorphism in the strains M129 and FH. J Bacteriol 177, 3370-3378.

Razin, S. (1979). Membrane proteins. In The Mycoplasmas, Vol. 1. Edited by M. F. Barile \& S. Razin. Washington, DC: American Society for Microbiology.

Ro, L.-H., Chen, R.-J. \& Shiuan, D. (1994). Rapid purification of antiserum against Mycoplasma byopneumoniae by an efficient absorption method. J Biochem Biophys Methods 28, 155-159.

Rosengarten, R. \& Yogev, D. (1996). Variant colony surface antigenic phenotypes within mycoplasma strain populations: implications for species identification and strain standardization. J Clin Microbiol 34, 149-158.

Ruoslahti, E. (1996). RGD and other recognition sequences for integrins. Annu Rev Cell Dev Biol 12, 697-715.

Sambrook, J., Fritsch, E. F. \& Maniatis, T. (1989). Molecular Cloning: a Laboratory Manual, 2nd edn. Cold Spring Harbor, NY: Cold Spring Harbor Laboratory.

Scarman, A. L., Chin, J. C., Eamens, G. J., Delaney, S. F. \&
Djordjevic, S.P. (1997). Identification of novel species-specific antigens of Mycoplasma hyopneumoniae by preparative SDSPAGE ELISA profiling. Microbiology 143, 663-673.

Stemke, G. W., Laiget, F., Grau, O. \& Bove, J. M. (1992). Phylogenetic relationships of the three porcine mycoplasmas, Mycoplasma byopneumoniae, Mycoplasma flocculare and Mycoplasma byorhinis and complete 16S rRNA sequence of $M$. flocculare. Int J Syst Bacteriol 42, 220-225.

Stemke, G. W., Phan, R., Young, T. F. \& Ross, R. F. (1994). Differentiation of Mycoplasma hyopneumoniae, $M$. flocculare and $M$. byorhinis on the basis of amplification of a $16 \mathrm{~S}$ rRNA gene sequence. Am J Vet Res 55, 81-84.

Strasser, M., Frey, J., Bestetti, G., Kobisch, M. \& Nicolet, J. (1991). Cloning and expression of a species-specific early immunogenic $36 \mathrm{kDa}$ protein of Mycoplasma byopneumoniae in E. coli. Infect Immun 59, 1217-1222.

Tajima, M. \& Yagihashi, T. (1982). Interaction of Mycoplasma byopneumoniae with the porcine respiratory epithelium as observed by electron microscopy. Infect Immun 37, 1162-1169.

Wästfelt, M., Stälhammar-Carlemalm, M., Delisses, A., Cabezon, T. \& Lindahl, G. (1996). Identification of a family of streptococcal surface proteins with extremely repetitive structure. J Biol Chem 271, 18892-18897.

Wieslander, Å., Boyer, M. J. \& Wróblewski, H. (1992). Membrane protein structure. In Mycoplasmas: Molecular Biology and Pathogenesis, pp. 93-112. Edited by J. Maniloff, R. N. McElhaney, L. R. Finch \& J. B. Baseman. Washington, DC: American Society for Microbiology.

Williamson, M. P. (1994). The structure and function of prolinerich regions in proteins. Biochem J 297, 249-260.

Wren, B. W. (1991). A family of clostridial and streptococcal ligand-binding proteins with conserved C-terminal repeat sequences. Mol Microbiol 5, 797-803.

Yamao, F., Muto, A., Kawauchi, Y., Iwami, M., Iwagami, S., Azumi, Y. \& Osawa, S. (1985). UGA is read as tryptophan in Mycoplasma capricolum. Proc Natl Acad Sci USA 82, 2306-2309.

Yang, Y. \& Gabriel, D. W. (1995). Intragenic recombinant of a single plant pathogen gene provides a mechanism for the evolution of new host specificities. J Bacteriol 177, 4963-4968.

Young, T. F., Chiang, Y.-W. \& Ross, R. F. (1990). Evaluation of local and systemic humoral immune responses to Mycoplasma byopneumoniae. Proceedings of the 11th Congress of the International Pig Veterinary Society, p. 97.

Young, T. F., Zhang, Q. \& Ross, R. F. (1992). Analysis of virulenceassociated antigens of Mycoplasma hyopneumoniae. Int Organ Mycoplasmol (IOM) Lett 2, 321.

Zar, J. H. (1984). Multiple comparisons. In Biostatistical Analysis, 2nd edn, pp. 108-205. New Jersey: Prentice Hall Inc.

Zhang, Q. \& Wise, K. S. (1996). Molecular basis of size and antigenic variation of a Mycoplasma hominis adhesin encoded by divergent vaa genes. Infect Immun 64, 2737-2744.

Zhang, Q., Young, T. F. \& Ross, R. F. (1994a). Microtitre plate adherence assay and receptor analogues for Mycoplasma byopneumoniae. Infect Immun 62, 1616-1622.

Zhang, Q., Young, T. F. \& Ross, R. F. (1994b). Glycolipid receptors for attachment of Mycoplasma byopneumoniae to porcine respiratory ciliated cells. Infect Immun 62, 4367-4373.

Zhang, Q., Young, T. F. \& Ross, R. F. (1995). Identification and characterisation of a Mycoplasma byopneumoniae adhesin. Infect Immun 63, 1013-1019.

Zheng, X., Teng, L. J., Watson, H. L., Glass, J. I., Blanchard, A. \& 
Cassell, G. H. (1995). Small repeating units within the Ureaplasma urealyticum $\mathrm{MB}$ antigen gene encode serovar specificity and are associated with antigenic size variation. Infect Immun 63, 891-898.

Zielinski, G. C. \& Ross, R. F. (1990). Effect on growth in cell cultures and strain on virulence of Mycoplasma byopneumoniae for swine. Am J Vet Res 51, 344-348.
Zielinski, G. C., Young, T. F. \& Ross, R. F. (1993). Adherence of Mycoplasma byopneumoniae to porcine ciliated respiratory tract cells. Am J Vet Res 54, 1262-1269.

Received 23 October 1997; revised 20 February 1998; accepted 30 March 1998. 